\title{
Impacts of Groundwater Constraints on Saudi Arabia's Low-Carbon Electricity Supply Strategy
}

\author{
Simon C. Parkinson, ${ }^{* \dagger,}$ Ned Djilali, ${ }^{\dagger, \S}$ Volker Krey, ${ }^{\ddagger}$ Oliver Fricko, ${ }^{\ddagger}$ Nils Johnson, ${ }^{\ddagger}$ Zarrar Khan, ${ }^{\star \prime}$ \\ Khaled Sedraoui, $^{\S}$ and Abdulrahman H. Almasoud ${ }^{\S}$ \\ ${ }^{\dagger}$ Institute for Integrated Energy Systems, University of Victoria, Victoria, British Columbia V8P 5C2, Canada \\ ${ }^{\ddagger}$ Energy Program, International Institute for Applied Systems Analysis, A-2361 Laxenburg, Austria \\ ${ }^{\S}$ Renewable Energy Research Group, King Abdulaziz University, Jeddah, Saudi Arabia \\ "Institute for Research in Technology, Universidad Pontificia Comillas, Madrid 28015, Spain
}

\section{Supporting Information}

ABSTRACT: Balancing groundwater depletion, socioeconomic development and food security in Saudi Arabia will require policy that promotes expansion of unconventional freshwater supply options, such as wastewater recycling and desalination. As these processes consume more electricity than conventional freshwater supply technologies, Saudi Arabia's electricity system is vulnerable to groundwater conservation policy. This paper examines strategies for adapting to long-term groundwater constraints in Saudi Arabia's freshwater and electricity supply sectors with an integrated modeling framework. The approach combines electricity and freshwater supply planning models across provinces to provide an improved representation of coupled infrastructure systems. The tool is applied to study the interaction between policy aimed at a complete phase-out of nonrenewable groundwater extraction and concurrent policy aimed at achieving deep reductions in electricity sector carbon emissions. We find that transitioning away from

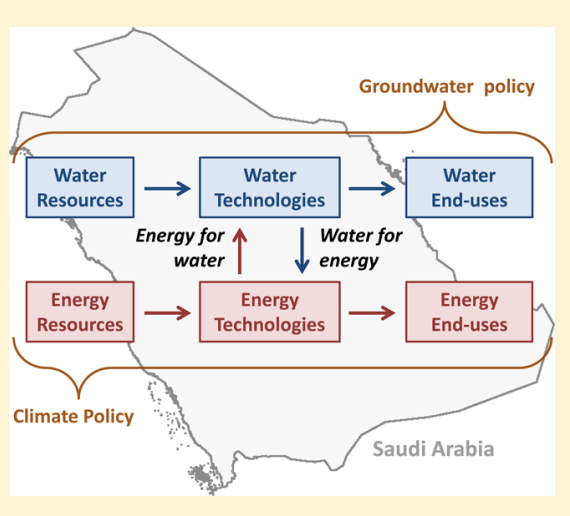
nonrenewable groundwater use by the year 2050 could increase electricity demand by more than $40 \%$ relative to 2010 conditions, and require investments similar to strategies aimed at transitioning away from fossil fuels in the electricity sector. Higher electricity demands under groundwater constraints reduce flexibility of supply side options in the electricity sector to limit carbon emissions, making it more expensive to fulfill climate sustainability objectives. The results of this analysis underscore the importance of integrated long-term planning approaches for Saudi Arabia's electricity and freshwater supply systems.

\section{INTRODUCTION}

Located on the Arabian Peninsula in Western Asia, the Kingdom of Saudi Arabia is a rapidly expanding economy of more than 28 million people. From 1990 to 2010, the average income in Saudi Arabia nearly doubled, ${ }^{1}$ and was accompanied by an average annual increase in urban electricity and freshwater demand of 7 and 3\%, respectively. ${ }^{2,3}$ With similar demographic trends projected moving forward, 4,5 there is concern surrounding increased consumption. The additional strain on the region's existing infrastructure will require expanded electricity and freshwater supply capacity. ${ }^{3,6,7}$ A key challenge facing regional planners is identification of a costeffective and sustainable long-term development strategy.

Compared to most other nations, Saudi Arabia contains relatively little exploitable surface water, and relies primarily on groundwater resources for its freshwater supply. ${ }^{3}$ Annual groundwater withdrawals of approximately $18 \mathrm{~km}^{3}$ exceed the estimated national renewable groundwater resource of $0.8-2.2$ $\mathrm{km}^{3}$, and are rapidly depleting long-term aquifer storage in the region. ${ }^{3,8-10}$ To mitigate the risk of freshwater scarcity, the country has developed more seawater desalination capacity than any other nation globally. ${ }^{10,11}$ Wastewater recycling also plays an important role in managing the region's freshwater challenges. $^{10,12}$ As desalination and wastewater recycling requires more electricity than conventional groundwater and surface water supply technologies, ${ }^{13,14}$ expanding capacity to balance groundwater constraints and urban growth will impact the regional electricity supply.

The bulk of electricity generation in Saudi Arabia is from oil burning thermal plants $\left(53 \%\right.$ in $\left.2010^{2}\right)$ that are carbon intensive. Increased electricity demand from the water sector thus exacerbates climate change risks. The region has abundant untapped renewable energy resources in the form of favorable solar, wind, and geothermal energy potentials. ${ }^{15-21}$ To meet increasing demands while decreasing carbon emissions, national energy policy calls for the development of over $50 \mathrm{GW}$ of new renewable electricity generation capacity by $2040 . .^{22,23}$

Received: November 27, 2015

Revised: January 16, 2016

Accepted: January 25, 2016 
Increased operational flexibility will support legislated solar and wind power integration, and is an electricity service market well-suited for an electrified freshwater supply. ${ }^{24-26}$ Thermal power plants can also require large amounts of freshwater for cooling and steam production, ${ }^{27}$ although regional freshwater scarcity has prompted implementation of alternative seawater and air cooling technologies throughout Saudi Arabia. ${ }^{28-30}$ Trade-offs with conventional freshwater cooling systems include increased implementation and maintenance costs, and reduced power generation efficiency. ${ }^{31-33}$

The existing linkages between Saudi Arabia's electricity and freshwater strategies, and the pressing need for a transition toward a more sustainable pathway, make an integrated electricity-freshwater supply strategy essential. A number of previous studies highlight cobenefits of systems integration. Analysis of regional technology deployment strategies find that solar-assisted desalination is already cost-effective in many locations throughout Saudi Arabia for the combined supply of low-carbon electricity and freshwater services. ${ }^{16,19}$ Opportunities to enhance operational efficiencies in coupled electricitywater supply systems through combined management have also been investigated for similar arid regions in the Middle East. $^{24,34}$ Recent analysis has also focused on the climate impacts of various water supply options in the U.S. under predefined electricity supply scenarios. ${ }^{35}$ Less explored are the interactions between electricity and freshwater systems during the planning of regional infrastructure capacity (supply technologies and networks). These investment decisions are important from the viewpoint of policy, as electricity and water supply infrastructures last for many decades and introduce structural inertia into the long-term development pathway. ${ }^{36}$ This quality of energy and water infrastructure requires prospective analysis of development strategies over decadal time-scales. ${ }^{8,36}$

Optimization models have emerged as key planning tools that enable system designers to explore long-term development pathways and the trade-offs among technology options. ${ }^{37,38}$ Many regional jurisdictions employ optimization models to develop integrated resource plans, ${ }^{39}$ and yet few combine longterm energy and water supply planning despite potential synergies. For example, previous research demonstrates that water supply planning models are sensitive to energy prices, ${ }^{37,40,41}$ and likewise electricity generation planning models are sensitive to water constraints, ${ }^{42-46}$ and waterrelated energy demand. ${ }^{6,26,47}$ Recent analysis of the Middle East region and China at a relatively coarse spatial and temporal resolution demonstrates the insights from and benefits of cooptimizing electricity and freshwater supply planning decisions. $^{48-50}$ This type of hard-linked optimization framework allows identification of pathways that hedge against undesirable interactions between electricity and freshwater systems, and provides a platform to explore technology portfolios that simultaneously balance energy and water sustainability objectives. Similar research underscores the importance of geography due to water distribution-related energy costs. ${ }^{47}$ These spatial effects are particularly important to consider in the case of Saudi Arabia because of the inland urban population lacking direct access to desalination opportunities available on the coast.

In this paper, we develop a modeling framework that cooptimizes electricity and freshwater supply planning decisions across spatially distributed regions to provide an improved representation of feedbacks between coupled infrastructure systems. The tool is applied to study impacts of groundwater management on the structure of the electricity system and the potential interplay with strategies aimed at reducing electricity sector climate impacts through deployment of low-carbon power generation. Results of this analysis provide important insight into the potential cost of policies and characteristics of technology portfolios that enable a transition toward a more sustainable system.

\section{MATERIALS AND METHODS}

We explore the interaction between long-term groundwater constraints and climate change mitigation objectives with a linear systems-engineering optimization model. We provide an overview of the salient features of the model in this section; the mathematical details are given in the Supporting Information (SI) (section S1 to S3). The modeling framework explicitly represents key electricity and water supply technologies in Saudi Arabia. Each technology is modeled as a linear inputoutput process where the consumption of resources and production of services are defined by average conversion factors. Technologies are coupled to form a closed system by accounting for the physical balance of resources across the modeled supply chain. A cost-optimization model calibrated to the existing national electricity and freshwater supply systems is then used to identify future infrastructure investments under projections of future demand and technology costs. The framework is applied across a number of scenarios to explore sensitivities to different national policy levers and model parametrizations.

Integrated Systems Modeling. The integrated systems model developed for the analysis is depicted in Figure 1. The supply systems are mapped as a series of electricity and water flows between technologies. The system boundary is defined such that hydro-climate data is used to parametrize water resource constraints, including the availability of surface water, groundwater and precipitation. Sector demand projections parametrize supply requirements. The water supply technologies included are reverse osmosis ( $\mathrm{RO}$ ) desalination, multistage flash (MSF) desalination, rainwater harvesting, groundwater withdrawals, and surface water withdrawals. These technologies convert raw water resources (seawater, precipitation, groundwater and surface water) into freshwater suitable for consumption within the different end-use sectors (agriculture, industrial and domestic). Water storage technologies included are surface reservoirs and potable water storage at end-use. Wastewater recycling is also included in the analysis, and enables upgrading of wastewater to potable quality. Water supply technologies interact with the electricity system through electricity intensity factors (e.g., $\mathrm{kWh}$ per $\mathrm{m}^{3}$ of potable water produced). The cost and energy intensity of water supply technologies are parametrized to include pretreatment and local distribution (Supporting Information, Table S4). ${ }^{13,14,51}$ Thermal energy requirements for MSF desalination technologies are also included and are supplied with the estimated excess heat from colocated thermal power generation, which is a common practice at modern combined-cycle plants in Saudi Arabia today. $^{52}$

Modeling of the electricity supply system parallels that of the water supply, and considers a number of different power plant technologies. Fossil fuel technologies (oil or natural gas) included are single- and combined-cycle steam turbines, and combustion turbines. We exclude carbon capture and storage technologies due to uncertainties surrounding costs and 
Electricity Supply Technology

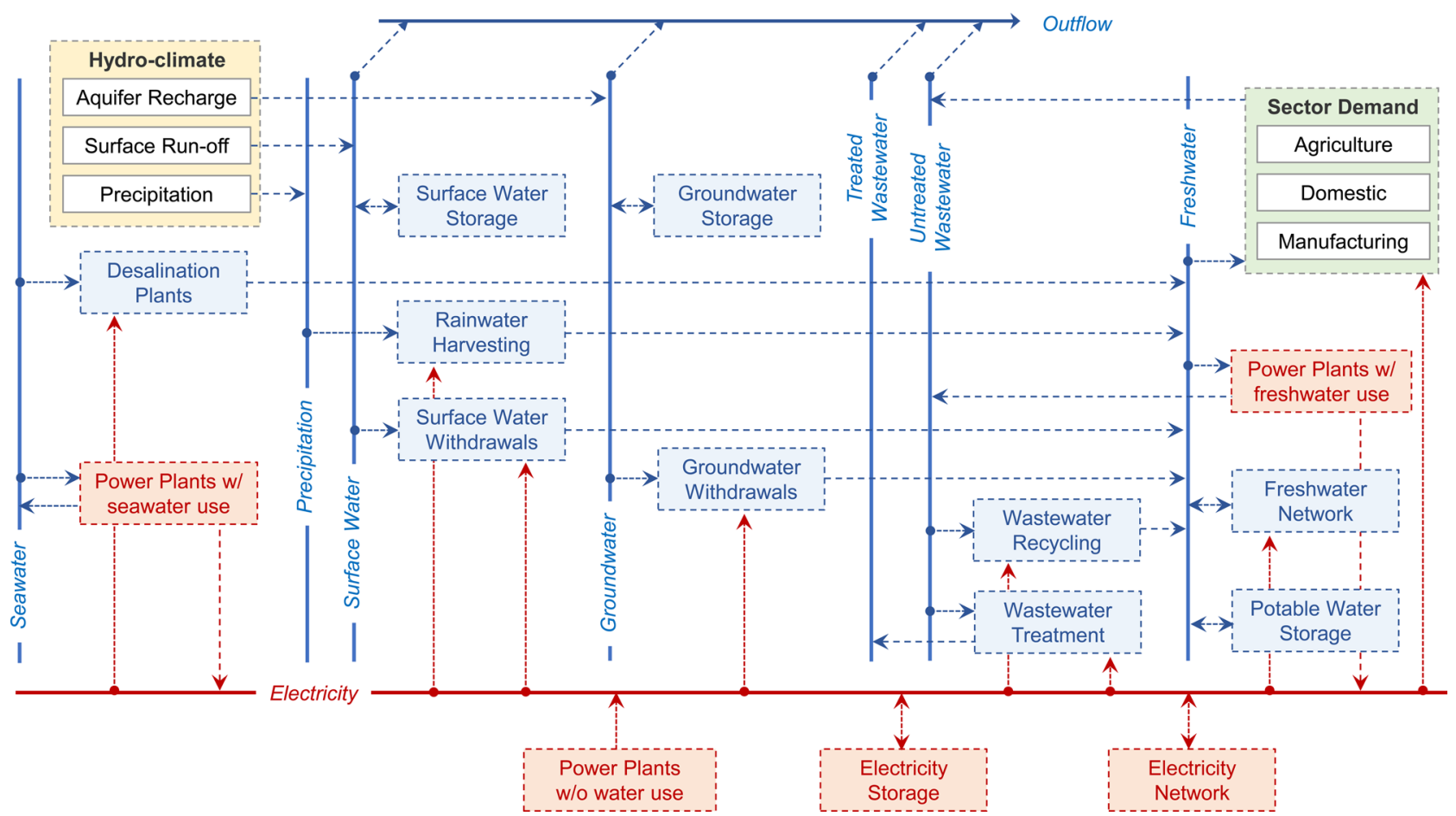

Figure 1. Integrated modeling of electricity and water supply systems. The systems are mapped as a series of flows between technologies. Each technology is modeled as a linear input-output process where the consumption of resources and production of services are defined by average conversion factors. Technologies are coupled to form a closed system by accounting for the physical balance of electricity and water flows across the modeled supply chain. The system boundary is defined such that existing hydro-climate data is used to parametrize water resource constraints, including the availability of surface water, groundwater and precipitation. Exogenous sector demand projections (manufacturing, domestic, and agriculture) parameterize supply requirements. The integrated system is represented in each province, with the network technologies allowing flow and trade of electricity and freshwater between provinces.

performance. Coal is also excluded due to its high emission intensity and expected impact on regional energy security (international imports would be required). Low-carbon technologies considered include nuclear, municipal waste-toenergy, geothermal, onshore wind, solar photovoltaic (PV), and concentrating solar power (CSP) with and without thermal storage. Thermal power plants (including CSP) are further distinguished by cooling technology to enable feedbacks to the water supply system. Once-through and closed-loop cooling systems utilizing freshwater are considered in the analysis, as well as air-cooled and seawater-cooled once-through systems. The volume of water withdrawn and the associated wastewater return flow is defined based on average water intensity factors (i.e., $\mathrm{m}^{3}$ of water per $\mathrm{kWh}$ generated). ${ }^{53}$ The choice of cooling system affects operating efficiency and investment costs, ${ }^{31-33}$ and these characteristics are explicitly included in the analysis by defining unique parameters for each type of cooling technology.

Constraints on peak and flexibility requirements of the electricity technology portfolio are defined to reflect operating constraints occurring between model periods (SI, section S1). ${ }^{54}$ We also distinguish flexible and base-load power plant operational modes to account for different operating costs and scheduling procedures that accompany flexible operation. ${ }^{55}$ Short-term electricity storage and load control technologies are also included in the analysis, and interact with the system by providing peak and flexibility reserve capacity. ${ }^{56}$ The potential for load control is dynamically linked to the total demand for electricity, allowing increased demand from the water sector to contribute to load control capabilities. The load control technologies are different from end-use conservation measures, which are addressed in the scenario analysis.

Long-distance transport of electricity and water is important to consider when comparing options for supply development. ${ }^{57-59}$ We incorporate spatial effects by disaggregating the study region into the 13 provincial administrative regions (SI, Figure S6). We chose this level of spatial disaggregation due to limited input data and computational efficiency. Expandable electricity and freshwater transmission between regions is included in the model with a simplified transport representation (i.e., the capacity of a network pathway is defined as a maximum amount of water or electricity that can be transferred over a given model period). Transmission losses are included (SI, Table S7). Energy for interprovincial water conveyance is estimated based on a recent analysis of long-distance desalination transport in the United States, ${ }^{60}$ and incorporates vertical and horizontal components of expected energy use (SI, S1.2). Distances and elevations between regions are inferred based on the locations of major provincial cities, with primary road transport connecting these cities used as a proxy for candidate network pathways. Elevation distances are calculated based on the altitude of major cities and do not incorporate the cumulative elevation change.

Although the majority of Saudi Arabia's population resides in urban areas $\left(82 \%\right.$ in $\left.2010^{1}\right)$, there remains a significant rural population. These individuals often lack access to the urban 
electricity and water supply infrastructures. We model the rural technologies separately to reflect these differences, with limitations set on the availability and cost of options. Rural electricity technologies considered in the model include diesel generators, solar PV and battery storage systems. For freshwater, rural areas are assumed to have access to groundwater, rainwater harvesting, and wastewater recycling technologies. ${ }^{61}$ Anticipated urbanization is included in the demand projections, allowing the analysis to address future migration toward urban areas. Electricity and freshwater trade between rural and urban areas is excluded.

Optimization. Optimization methods are used to solve for the capacity (design) and output (activity) of technologies included in the model (SI, section S1). The objective of the optimization is to minimize cumulative discounted costs of water and electricity supply systems over the planning horizon, with technology investment, fixed/variable O\&M, and fuel costs considered in the system cost accounting. This type of cost-optimization model is common in national infrastructure planning, ${ }^{38,39}$ and could be extended to include risk metrics or multiobjective formulations. Similar to the approach proposed in Dubreuil et al. (2013), ${ }^{48}$ we represent both water and electricity supply technologies and solve for the design and activity variables simultaneously. Climate and groundwater objectives are modeled as constraints on carbon emissions and groundwater withdrawals. A planning horizon of 2010-2050 in 5 -year segments is selected for the analysis to explore impacts of national policy and path-dependency on technology deployment. Each modeled year is broken into monthly timeslices to enable treatment of seasonal effects, such as the potential mismatch between available supply and demand. Intertemporal optimization is used to solve for each time-step concurrently.

Parameterization. A significant amount of input data is required to parametrize the model, and is detailed in the SI (section S2). We specifically calibrate the model to existing conditions by identifying the capacity, vintage, and location of existing and committed infrastructure from regional planning documents and recent resource assessments (SI, Tables S3, S5 and S8). ${ }^{6,10,13,28,29,62-64}$ Cost and performance data for supply technologies are taken from a number of recent technology assessments (SI, Tables S2, S4 and S7). ${ }^{13,14,51,53,61,65-71}$ Future fuel costs are estimated using domestic prices from a previous regional planning study, ${ }^{6}$ and growth rates for the Middle East North Africa (MENA) region projected from a global integrated assessment model. ${ }^{72}$ Due to regional water scarcity and lack of data, we assume that all thermal power generation in 2010 located in coastal regions are seawater-cooled and all thermal generation in 2010 located inland are air-cooled. Technical documentation for large-scale plants support this assumption. $^{28-30}$

Demand Projections. Demands for electricity and water from the coupled supply technologies are endogenous to the cost-optimization model. Limited data is available to parametrize the diverse set of technologies and consumers existing in the domestic, agriculture, and manufacturing sectors. We therefore treat these demands as exogenous and define a number of scenarios to explore uncertainties surrounding conservation potential. Econometric models linking socioeconomic development to consumption are typically used to generate exogenous electricity and freshwater demand projections, ${ }^{6,16,39}$ and we apply a similar approach to generate demands for Saudi Arabia. The demand models estimate agriculture, manufacturing and domestic electricity and freshwater consumption based on projected population, urbanization, GDP and rate of technological change (i.e., improved efficiency over time). The model identification process and parametrization is summarized in the SI (section S3). Corresponding wastewater volumes from the industrial and domestic sectors are estimated with national consumption efficiencies (the fraction of water withdrawn that is consumed) from a previous global analysis. ${ }^{73}$

For the projections, we use population, urbanization, and GDP trajectories aligned with the shared socioeconomic pathways (SSP). ${ }^{4,5,74,75}$ We specifically focus on the SSP2 scenario, a midrange case reflecting a continuation of current trends (moderate sustainability policy and technology shifts). Although SSP2 is a moderate scenario (globally), in the specific case of Saudi Arabia it corresponds to substantial population and economic activity growth. ${ }^{4,5}$ We utilize the quantitative SSP scenario data to generate a reference national-level electricity and freshwater demand trajectory for each sector (agriculture, manufacturing, and domestic) out to 2050. The results are depicted in Figure 2 and project an average annual growth rate for urban electricity demand of $3 \%$. The trajectories are more conservative than other recent projections, ${ }^{22}$ and suggest the existing renewable energy deployment strategy (50 GW by 2040) will accommodate load growth and not reduce aggregate electricity sector emissions.

Water demands remain relatively constant reflecting large reductions in per capita irrigation. Nevertheless, desalination would be needed to support the reference irrigation demand under aggressive groundwater conservation, which represents a significant and costly transformation pathway. Similar development has occurred in Spain and Israel, where the desalinated seawater enables production of high-value fruits and vegetables in areas facing water scarcity. ${ }^{76}$ Recent analysis of Saudi Arabia's agricultural policy suggests a shift toward increased production of similar crops to promote national food security. ${ }^{77}$ It therefore seems likely that Saudi Arabia would consider largescale seawater desalination as a potential supply option for irrigation.

When desalinated seawater or recycled wastewater is used for irrigation, additional care must be taken to replace nutrients stripped during the treatment process that are important for soil quality. ${ }^{78,79}$ These additional costs are excluded from the assessment due to lack of data.

The estimated national domestic and industrial demands are downscaled to the provincial level based on the population distribution, whereas agriculture demands are disaggregated following the historical provincial distribution. ${ }^{80}$ Future monthly domestic electricity demands are decomposed based on historical trends. ${ }^{22}$ Domestic and irrigation water demands are broken into monthly components based on the estimated monthly average soil moisture deficit, which is calculated across $1 / 4$ degree grid cells and weighted based on population for domestic demands. ${ }^{81}$

Scenarios. The model is applied across a number of scenarios to explore: (1) trade-offs and synergies between groundwater and climate policy; and (2) sensitivity to uncertainties in model parameterization. The impact of national groundwater policy on the electricity and freshwater supply systems is explored by varying the allowable annual extraction in each model region. It is estimated that at current extraction rates approximately 50 years of fossil groundwater remains in Saudi Arabia, ${ }^{13,82}$ although estimates vary widely across the 

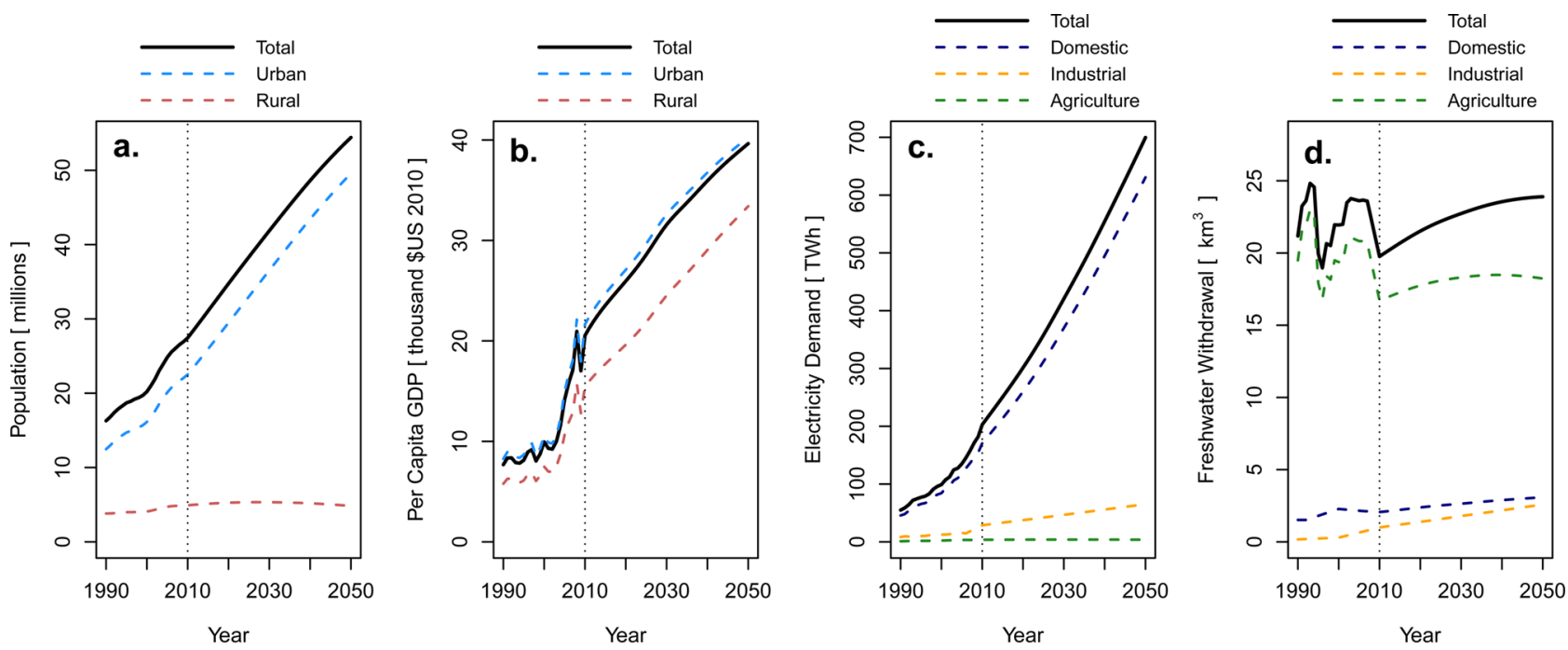

Figure 2. National socioeconomic and demand projections for the SSP2 scenario. a. Population; b. Per capita GDP in purchasing power parity (PPP); c. Electricity demand; and d. Freshwater withdrawal. Industrial demands exclude electricity for desalination and cooling water for thermoelectric generation.

literature. ${ }^{10}$ We initially explore the midcentury time frame by constraining the allowable extraction in each region along a linear trajectory that results in national annual groundwater withdrawals reducing from $18 \mathrm{~km}^{3}$ in 2010 to $1.6 \mathrm{~km}^{3}$ in 2050 (i.e., a $91 \%$ reduction). This would correspond to an annual extraction rate in 2050 that falls within estimates of the renewable recharge. ${ }^{10,80}$ This also corresponds to a depletion of remaining nonrenewable groundwater reserves of approximately $330 \mathrm{~km}^{3}$ by 2050 , which is within recent estimates of the available resource. ${ }^{10}$ It is important to note that further investigation into the distributed aquifer response via long-term hydrogeological modeling should be pursued to fully understand the implications for groundwater sustainability. ${ }^{8,83}$

We also explore potential interplays with increasingly ambitious climate policy. Limiting 21 st century climate change to $2{ }^{\circ} \mathrm{C}$ over preindustrial levels will require widespread transformation of the electricity system. ${ }^{72}$ We construct scenarios for Saudi Arabia by simulating stringent mitigation policies that are constrained to achieve an $80 \%$ reduction in cumulative carbon emissions as compared to unconstrained conditions by the year 2050. Sensitivity to simultaneous groundwater and climate objectives are then examined by simulating different combinations of increasingly stringent policy scenarios. Each policy objective is varied between a baseline ( $0 \%$ fulfillment) and a $100 \%$ fulfillment case in increments of $50 \%$. As groundwater is already overexploited, the baseline constrains withdrawals to 2010 levels. The results of this analysis provide insight into how costs and technology deployment patterns vary based on groundwater and climate policy ambition.

To investigate results sensitivity to uncertain model parameters, the cost-optimization model is applied across the scenarios listed in Table 1. The Reference scenario considers average performance parameters and the exogenous demands depicted in Figure 2. Uncertainties surrounding the scale of the available groundwater resource are explored by parametrizing a conservative scenario that shifts the $91 \%$ reduction target to the year 2030. An additional scenario considers a $50 \%$ capital cost subsidy to renewable electricity generation, and is meant to reflect a situation where market conditions are improved with

\section{Table 1. Summary of Scenarios Explored in the Analysis}

\begin{tabular}{|c|c|}
\hline scenario & model implementation \\
\hline reference & $\begin{array}{l}\text { reference demand trajectories, performance/cost } \\
\text { parameters follow averages from the literature }\end{array}$ \\
\hline $\begin{array}{l}2030 \\
\text { groundwater } \\
\text { target }\end{array}$ & the groundwater target year is shifted from 2050 to 2030 \\
\hline $\begin{array}{l}\text { low-cost } \\
\text { renewables }\end{array}$ & $\begin{array}{l}\text { investment costs for renewables are reduced by } 50 \% \text { relative } \\
\text { to the reference scenario }\end{array}$ \\
\hline $\begin{array}{l}\text { water } \\
\text { conservation }\end{array}$ & $\begin{array}{l}\text { exogenous freshwater demands are reduced by } 40 \% \text { in } 2050 \\
\text { relative to the reference scenario }\end{array}$ \\
\hline $\begin{array}{l}\text { electricity } \\
\text { conservation }\end{array}$ & $\begin{array}{l}\text { exogenous electricity demands are reduced by } 40 \% \text { in } 2050 \\
\text { relative to the reference scenario }\end{array}$ \\
\hline $\begin{array}{l}\text { increased food } \\
\text { imports }\end{array}$ & $\begin{array}{l}\text { agriculture freshwater withdrawals are reduced by } 50 \% \\
\text { relative to the reference scenario }\end{array}$ \\
\hline $\begin{array}{l}\text { efficient water } \\
\text { supply }\end{array}$ & $\begin{array}{l}\text { water supply technologies set to the lowest energy intensity } \\
\text { from the literature }\end{array}$ \\
\hline optimistic & $\begin{array}{l}\text { electricity and water conservation, increased food imports } \\
\text { and efficient water supply }\end{array}$ \\
\hline
\end{tabular}

external financial support. The remaining scenarios explore demand uncertainties. Although the reference demand trajectories include improvements in energy efficiency, advanced conservation scenarios are defined to reflect uncertainties surrounding technological change, price response, and end-use behavior (SI Figures S2 and S3). Exogenous demands in the advanced conservation scenarios decrease $40 \%$ by the year 2050 relative to the reference scenario. This represents a potential for water and electricity conservation similar to that identified in recent analyses. $13,47,84,85$ The potential impacts of alternative food import policies on national irrigation withdrawals are also important to consider due to the fraction of total freshwater demand applied for irrigation. We explore a scenario investigating the potential for increased food imports to displace unconventional water resource expansion by simulating a $50 \%$ reduction in irrigation withdrawals by 2050 (SI Figure S4). The electricity intensity of water supply technologies is also uncertain, and we explore the potential for enhanced performance to impact the results by including a scenario parametrized with the lowest energy intensities from the literature (SI Table S4). Finally, we combine all 


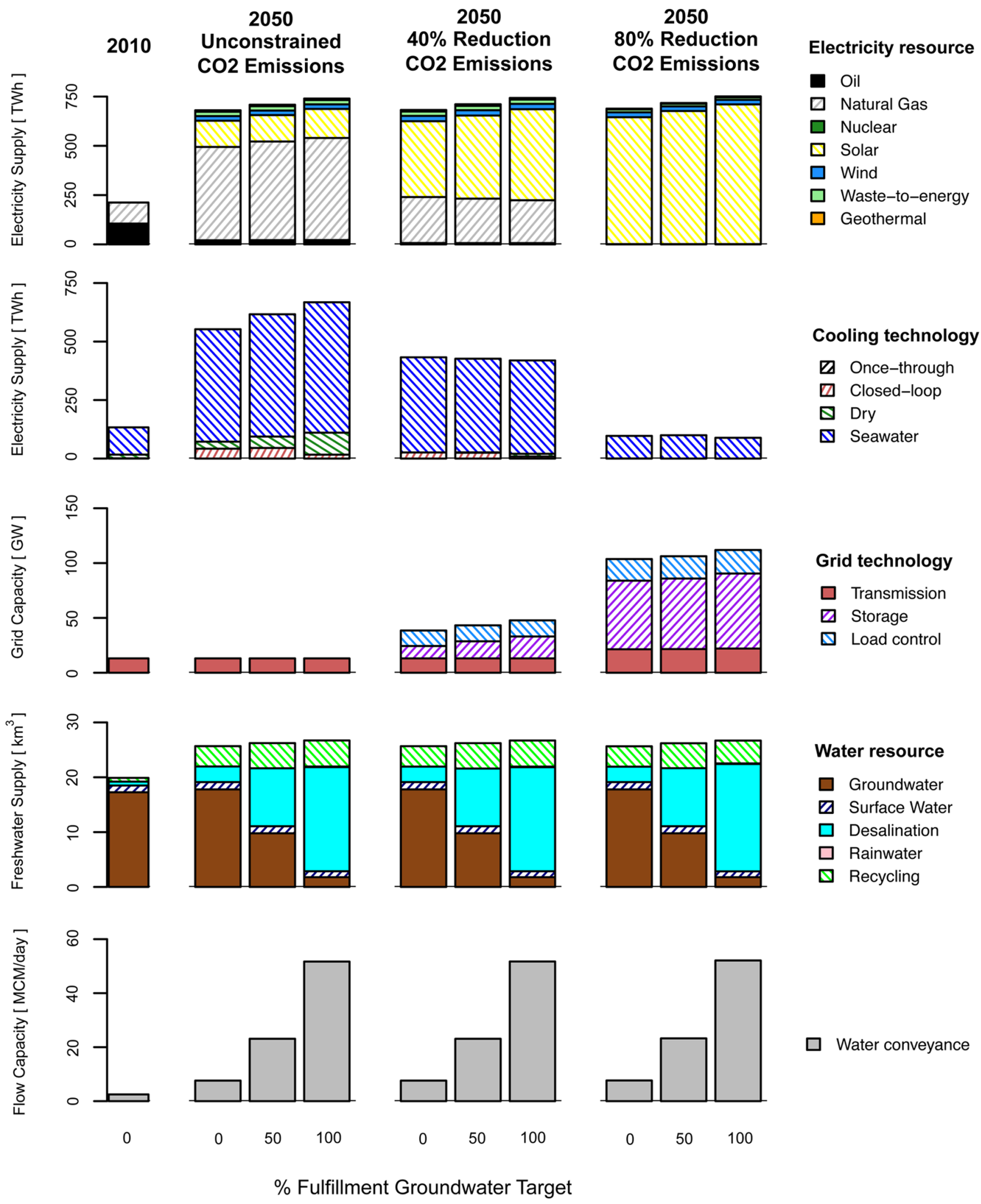

Figure 3. Optimal supply mixes and network technology capacities aggregated to the national-scale for the year 2050 across the groundwater and climate policy objectives investigated. The groundwater target represents a $91 \%$ reduction in annual groundwater withdrawals in 2050 relative to 2010 .

conservation measures and efficient water supply assumptions to generate an Optimistic development scenario (SI Figure S5).
All scenarios include Saudi Arabia's existing renewable energy deployment strategy that involves integration of over $50 \mathrm{GW}$ of 
renewable power generation by 2040 . The strategy includes the following technology-specific targets: $25 \mathrm{GW}$ of CSP, $16 \mathrm{GW}$ of solar PV, $9 \mathrm{GW}$ of wind, $3 \mathrm{GW}$ of waste-to-energy, and $1 \mathrm{GW}$ of geothermal. ${ }^{22}$ We model this policy by constraining the capacity from the associated technologies to exceed an annual deployment target in each simulated year. The target capacity development represents a linear trajectory fitted between current levels and the 2040 goal.

\section{RESULTS}

We initially focus on analyzing the implications of simultaneous groundwater and emission constraints on supply and network technology development for the Reference scenario. Depicted in Figure 3 are the optimal supply mixes and network technology capacities aggregated to the national-scale for the year 2050 across the groundwater and climate policy objectives simulated. Provincial results are included in the SI (section S4.2).

The rapid growth in electricity demand and retirement of existing units results in a complete redesign of the electricity generation portfolio. When carbon emissions are unconstrained, combined-cycle natural gas plants makeup the largest portion of new capacity due to the relatively low investment cost. The capacity is deployed primarily in coastal regions to access seawater for cooling. A relatively small amount of capacity employing closed-loop freshwater cooling is also deployed in Asir: a province lacking coastlines but with a relatively high per capita availability of surface water resources. Air-cooled combined-cycle generation and combustion turbines are deployed in the remaining provinces to help support load growth without expanding transmission. Existing renewable energy policy (50 GW of installed capacity by 2040) results in wind, geothermal, solar PV, and CSP expansion. The CSP capacity is deployed in coastal regions due to the accessibility of seawater for cooling. Rural areas combine diesel generators with PV capacity to meet the stagnating demand growth anticipated under the SSP2 urbanization scenario. The constraint on groundwater withdrawals in the reference case to remain at or below 2010 levels results in an increase in wastewater recycling and desalination capacity, and expansion of the water conveyance infrastructure beyond 2010 levels is needed to transport desalinated water inland.

Policy that reduces cumulative carbon emissions in 2050 by $80 \%$ relative to the unconstrained scenario triggers an electricity system transformation. All regions rapidly deploy solar technologies to reduce emissions, and utilize a combination of conventional storage and load control technologies to maintain system reliability. PV technology expands particularly quickly under the parametrized cost improvements. Seawater withdrawals reduce significantly under PV expansion due to the displacement of seawater-cooled thermal generation. Electricity transmission capacity is reinforced to support matching seasonal solar and load coincidence across provinces. The electricity system transformation is found to have a relatively modest impact on the structure of the water supply. The largest difference compared to the unconstrained emissions case is a small increase in wastewater recycling.

Policy that reduces annual groundwater withdrawals in 2050 by $91 \%$ relative to 2010 results in a significant transformation of the water supply system. RO desalination capacity expands rapidly in coastal provinces, and all regions utilize available wastewater for recycling. The interprovincial water network is developed more extensively to support inland transfer of desalinated water from coastal regions, and a greater volume of water must be produced to overcome distribution losses. The regional distribution of electricity technologies shift toward increased capacity of power generation in coastal regions where desalination occurs. The increased electricity demand from desalination and water conveyance impacts the electricity transmission configuration, with larger capacity corridors developed between regions connecting high-quality inland solar energy resources with coastal desalination opportunities. More investment into load control technologies also occurs due to greater resource availability accompanying the increased water sector electricity demand.

In the baseline scenario (no emissions or groundwater reduction targets), water sector electricity use increases from 15 TWh in 2010 to $22 \mathrm{TWh}$ in 2050 (3\% of total national electricity demand). The majority of water sector electricity use in this case is from groundwater (11 TWh), with the remaining balance mainly attributed to desalination (6 TWh), recycling ( 3 TWh) and conveyance ( 2 TWh). Electricity requirements increase rapidly with stringency of the groundwater constraint. In the scenario where groundwater withdrawals are reduced by $91 \%$ in 2050 , the freshwater supply sector represents $12 \%$ (92 TWh) of total final electricity demand. For perspective, this represents more than $40 \%$ of the total national electricity demand in 2010. The majority of increased electricity use comes from desalination (67 TWh), water conveyance (19 $\mathrm{TWh}$ ) and wastewater recycling (4 TWh), with groundwater electricity demand dropping significantly ( $1 \mathrm{TWh})$. The freshwater allocated to the electricity system is less intuitive. Most freshwater is used in the unconstrained emissions scenario to support closed-loop cooled natural gas generation located inland, with a small amount persisting in the intermediate scenario despite increasingly stringent groundwater constraints. Nevertheless, freshwater allocated to the electricity sector in the most extreme case represents less than $1 \%$ of projected national demand across all sectors in 2050, suggesting a relatively minor role in future freshwater supply requirements.

Transitioning to $100 \%$ fulfillment of the groundwater conservation objective without climate policy results in costs increasing $46 \%$ compared to the baseline scenario. Under 2010 groundwater withdrawals, reducing cumulative carbon emissions by $80 \%$ increases discounted costs by $51 \%$. Combining the $91 \%$ groundwater reduction and the $80 \%$ emission reduction policies results in costs increasing by $101 \%$. The main challenge under combined policy objectives is the need to simultaneously increase electricity supply capacity to allow for increased electricity demand due to desalination, wastewater recycling and water conveyance, while decreasing carbon intensity to maintain cumulative electricity sector carbon emissions. It is important to note that some of the benefits and costs associated with these scenarios are excluded (e.g., conservation measures, climate damages, reduced air pollution, avoided water shortages, etc.).

Further sensitivity analysis is performed by examining the results obtained across the different scenarios listed in Table 1. We specifically explore uncertainties surrounding future costs by varying the technology cost assumptions across a suitable range identified in the literature (SI, Table S9). ${ }^{70}$ Figure 4 depicts the percent change in discounted system costs relative to the unconstrained baseline scenario (i.e., no cumulative emissions constraint, groundwater extraction limited to 2010 rates, reference demand trajectories, and average cost/performance parameters for technologies). System costs increase in the 


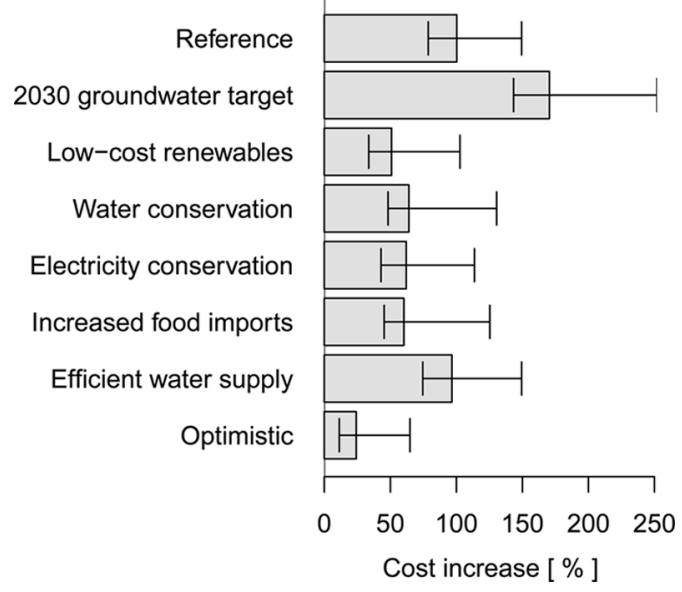

Figure 4. Sensitivity to technology cost parametrization for the scenarios listed in Table 1. The horizontal bars represent results obtained with average cost parameters. The error bars span the results obtained with the minimum and maximum cost parameters. Each scenario considers $100 \%$ fulfillment of the groundwater and climate objectives (91\% reduction in groundwater withdrawals and $80 \%$ reduction in cumulative carbon emissions). The cost increase is calculated as a percent change relative to the unconstrained baseline scenario (i.e., no cumulative emissions constraint, groundwater extraction limited to 2010 rates, reference demand trajectories and average cost/performance parameters for technologies).

reference scenario between 79 and $149 \%$ relative to the unconstrained scenario. Nuclear generation expands when the least optimiztic technology costs are assumed due to the slow cost improvement for solar generation and advanced grid technologies (load control and storage). Major cost savings are achieved in the "Low-cost renewables" scenario. PV and CSP become more attractive as a generating option, and expand across all regions to prevent transmission development despite the geographic diversity modeled between provinces. When the groundwater target year is shifted to a more conservative 2030 fulfillment time frame, investment into unconventional water resource options is accelerated earlier in the planning horizon, leading to large increases in system costs. The scenarios involving reduced demands achieve significant savings, whereas the enhanced water supply performance scenario displays less impact. The "Optimistic" scenario, combining the conservation and efficient water supply parametrizations, results in a supply portfolio that costs $11-65 \%$ more than the unconstrained case, thus representing considerable savings when compared to the costs obtained for the reference scenario.

\section{DISCUSSION}

Many parts of the world face increasing groundwater stress that will necessitate the deployment of alternative electricityintensive water infrastructure, such as desalination, wastewater recycling, and long-distance water transfers. Saudi Arabia is one of the most severely constrained jurisdictions in this respect and provides a challenging case study for exploring trade-offs between electricity and freshwater systems. In this paper, we developed a new modeling framework that hard-links electricity and freshwater investment decisions across provinces to provide an improved representation of feedbacks between coupled infrastructure systems. The framework was applied to explore impacts of groundwater constraints on the structure of electricity and freshwater supply in Saudi Arabia, and the potential interplay with climate policy aimed at reducing electricity sector carbon emissions.

Our results suggest that strategies aimed at achieving deep reductions in nonrenewable groundwater extraction will lead to fundamental changes in regional electricity system design. Large-scale expansion of desalination and regional water distribution capacity emerges as a critical infrastructure solution enabling displacement of groundwater withdrawals while supporting growth in urban freshwater demand. The required infrastructure increases water sector electricity-intensity and migrates electricity demand from distributed groundwater pumping stations to coastal desalination plants. The reconfiguration of demand benefits thermal generation, due to the ability to colocate with desalination plants and access seawater for cooling. Protecting coastal ecosystems from the increased industrial activity (e.g., thermal water pollution) will pose additional constraints to technology development that were unexplored in this analysis, and important to address in future research.

Our results further suggest that strategies aimed at mitigating nonrenewable groundwater extraction are likely to require similar investment as strategies aimed at limiting fossil fuel use in the electricity sector. The increased water supply costs follow from the required ramp-up in desalination and water distribution investments. When emission constraints are also considered, we find that higher electricity demands under groundwater constraints reduce flexibility of supply side options in the electricity sector to limit carbon emissions. The need to simultaneously increase electricity supply capacity while reducing carbon intensity make it more expensive to fulfill climate change mitigation objectives under groundwater constraints. The integrated planning framework incorporating investment and operation across provinces is crucial to identifying these trade-offs, and underscores the importance of a systems perspective when assessing suitability of supply options across the electricity-water nexus.

Results incorporating optimistic demand projections indicate the significant potential for end-use conservation to enable a low-cost transition away from nonrenewable groundwater use and toward a low-carbon electricity system. Potential policy instruments targeting demand reductions include increased prices or end-use efficiency standards. Our assessment also demonstrates the sensitivity of the optimal system configuration to uncertainties surrounding groundwater constraints and technology costs. To provide further insight into robust strategies, future work should consider endogenous representations of these key uncertainties in the optimization model. Finally, the importance of agricultural policy suggests the framework would benefit from incorporating land-use decisions. This approach would enable consideration of adaptive land management to address concerns surrounding desalination and national food security.

\section{ASSOCIATED CONTENT}

\section{S Supporting Information}

This material is available free via the Internet at The Supporting Information is available free of charge on the ACS Publications website at DOI: 10.1021/acs.est.5b05852.

Additional details regarding the optimization methods and input data, as well as additional scenario results (PDF) 


\section{AUTHOR INFORMATION}

\section{Corresponding Author}

*Phone: 1-250-721-6295; e-mail: scp@uvic.ca.

\section{Notes}

The authors declare no competing financial interest.

\section{ACKNOWLEDGMENTS}

Funding and technical support for this work was provided in part by the Deanship of Scientific Research, King Abdulaziz University, Jeddah, under grant no. (1-135-36-HiCi). S.P. was also supported by a postgraduate scholarship from the Natural Sciences \& Engineering Research Council of Canada. We thank Kevin Ummel for providing assistance with data processing in $\mathrm{R}$, and Peter Kolp for providing support with the CPLEX optimization software.

\section{REFERENCES}

(1) World Bank. World Bank Indicators, 2014. http://data. worldbank.org/indicator (accessed: 2015-10-11).

(2) IEA, International Energy Agency Statistics: Saudi Arabia, 2014. http://www.iea.org/countries/non-membercountries/saudiarabia/ (accessed: 2015-06-10).

(3) Food and Agriculture Organization of the United Nations. Groundwater Management in Saudi Arabia: Draft Synthesis Report, 2009.

(4) Samir, K.; Lutz, W. The human core of the shared socioeconomic pathways: Population scenarios by age, sex and level of education for all countries to 2100 Global Environ. Change 2014, In press, 112.10.1016/j.gloenvcha.2014.06.004

(5) Dellink, R.; Chateau, J.; Lanzi, E.; Magne, B. Long-term economic growth projections in the Shared Socioeconomic Pathways Global Environ. Change 2015, 1-15.10.1016/j.gloenvcha.2015.06.004

(6) Center for Engineering Research. Updated Generation Planning for the Saudi Electricity Sector, 2006.

(7) MEP. Ministry of Economics and Planning, Saudi Arabia Ninth National Development Plan. 2009.

(8) Gleeson, T.; Wada, Y.; Bierkens, M. F.; van Beek, L. P. Water balance of global aquifers revealed by groundwater footprint. Nature 2012, 488, 197-200.

(9) Joodaki, G.; Wahr, J.; Swenson, S. Estimating the human contribution to groundwater depletion in the Middle East, from GRACE data, land surface models, and well observations. Water Resour. Res. 2014, 50, 2679-2692.

(10) Chowdhury, S.; Al-Zahrani, M. Characterizing water resources and trends of sector wise water consumptions in Saudi Arabia. J. King Saud Univ., Eng. Sci. 2015, 27, 68-82.

(11) Gleick, P. The World's Water; Pacific Institute, 2009.

(12) Zahid, W. M. Wastewater Treatment Technologies For Water Reuse In Saudi Arabia. In The 2nd Saudi International Water Technology Conference; King Abdulaziz City for Science and Technology. 2014.

(13) Kajenthira, A.; Siddiqi, A.; Anadon, L. D. A new case for promoting wastewater reuse in Saudi Arabia: Bringing energy into the water equation. J. Environ. Manage. 2012, 102, 184-192.

(14) Ghaffour, N.; Missimer, T. M.; Amy, G. L. Technical review and evaluation of the economics of water desalination: current and future challenges for better water supply sustainability. Desalination 2013, 309, 197-207.

(15) Rehman, S.; Ahmad, A. Assessment of wind energy potential for coastal locations of the Kingdom of Saudi Arabia. Energy 2004, 29, $1105-1115$

(16) Trieb, F.; Müller-Steinhagen, H. Concentrating solar power for seawater desalination in the Middle East and North Africa. Desalination 2008, 220, 165-183.

(17) Taleb, H. Barriers hindering the utilisation of geothermal resources in Saudi Arabia. Energy Sustainable Dev. 2009, 13, 183-188.
(18) Ummel, K. Global prospects for utility-scale solar power: toward spatially explicit modeling of renewable energy systems. Center for Global Development Working Paper 2010, DOI: 10.2139/ssrn.1824543.

(19) Bilton, A. M.; Wiesman, R.; Arif, A.; Zubair, S. M.; Dubowsky, S. On the feasibility of community-scale photovoltaic-powered reverse osmosis desalination systems for remote locations. Renewable Energy 2011, 36, 3246-3256.

(20) Shaahid, S.; Al-Hadhrami, L.; Rahman, M. Economic feasibility of development of wind power plants in coastal locations of Saudi Arabia: A review. Renewable Sustainable Energy Rev. 2013, 19, 589597.

(21) Hussein, M. T.; Lashin, A.; Al Bassam, A.; Al Arifi, N.; Al Zahrani, I. Geothermal power potential at the western coastal part of Saudi Arabia. Renewable Sustainable Energy Rev. 2013, 26, 668-684.

(22) KACARE. King Abdullah City for Atomic and Renewable Energy, Saudi Arabia's Renewable Energy Strategy and Solar Energy Deployment Roadmap. 2012.

(23) Dipaola, A. Saudi Arabia Delays $\$ 109$ Billion Solar Plant by 8 Years, 2015. http://www.bloomberg.com/news/articles/2015-01-20/ saudi-arabia- \delay-109-billion-solar-plant-by-8-years (accessed: 201507-21).

(24) Al-Nory, M.; El-Beltagy, M. An energy management approach for renewable energy integration with power generation and water desalination. Renewable Energy 2014, 72, 377-385.

(25) Letto, D.; Snowling, S.; George, R.; Morrissey, C.; Andres, H.; Fox, C. Creating New Revenue With Existing Processes: Evaluating Grid Balance With Demand-side Loads At Wastewater Treatment Plants Using Dynamic Modeling. Proceedings of the Water Environment Federation 2012, 2012, 4301-4322.

(26) Novosel, T.; Ćosić, B.; Pukšec, T.; Krajačić, G.; Duić, N.; Mathiesen, B.; Lund, H.; Mustafa, M. Integration of renewables and reverse osmosis desalination: Case study for the Jordanian energy system with a high share of wind and photovoltaics. Energy 2015, 92, 270-278.

(27) Sanders, K. T. Critical review: Uncharted waters? The future of the electricity-water nexus. Environ. Sci. Technol. 2014, 49, 51-66.

(28) Alstom. Alstom Case Study: Gas Product Solutions, Riyadh 12 Saudi Arabia, 2013.

(29) ACWA Power International. Combined Qurayyah IPP1 and 2: Addendum to Social and Environmental Assessment Report, 2011.

(30) MAC Construction. PP9 1200 MW Combined-cycle Power Station, 2012.

(31) Gerdes, K.; Nichols, C. NETL: Water Requirements for Existing and Emerging Thermoelectric Plant Technologies, 2009.

(32) Turchi, C.; Wagner, M.; Kutscher, C. Water Use in Parabolic Trough Power Plants: Summary Results from WorleyParsons' Analyses. NREL 2010, 1-25.

(33) Zhang, C.; Anadon, L. D.; Mo, H.; Zhao, Z.; Liu, Z. Watercarbon trade-off in China's coal power industry. Environ. Sci. Technol. 2014, 48, 11082-11089.

(34) Santhosh, A.; Farid, A. M.; Youcef-Toumi, K. Real-time economic dispatch for the supply side of the energy-water nexus. Appl. Energy 2014, 122, 42-52.

(35) Mo, W.; Wang, R.; Zimmerman, J. B. Energy-Water Nexus Analysis of Enhanced Water Supply Scenarios: A Regional Comparison of Tampa Bay, Florida, and San Diego, California. Environ. Sci. Technol. 2014, 48, 5883-5891.

(36) Schrattenholzer, L.; Miketa, A.; Riahi, K.; Roehrl, R. A. Achieving a Sustainable Global Energy System: Identifying Possibilities Using LongTerm Energy Scenarios; Edward Elgar Publishing, 2004.

(37) Atilhan, S.; Mahfouz, A. B.; Batchelor, B.; Linke, P.; AbdelWahab, A.; Nápoles-Rivera, F.; Jiménez-Gutiérrez, A.; El-Halwagi, M. M. A systems-integration approach to the optimization of macroscopic water desalination and distribution networks: a general framework applied to Qatar's water resources. Clean Technol. Environ. Policy 2012, $14,161-171$.

(38) Bhattacharyya, S. C.; Timilsina, G. R. A review of energy system models. International Journal of Energy Sector Management 2010, 4, 494-518. 
(39) Swisher, J.; Martino-Jannuzzi, G.; Redlinger, R. Tools and Methods for Integrated Resource Planning: Improving Energy Efficiency and Protecting the Environment, 1997.

(40) Matsumoto, J.; Mays, L. W. Capacity Expansion model for largescale water-energy systems. Water Resour. Res. 1983, 19, 593-607.

(41) Scott, C. A. The water-energy-climate nexus: Resources and policy outlook for aquifers in Mexico. Water Resour. Res. 2011, 47, 118.

(42) Webster, M.; Donohoo, P.; Palmintier, B. Water-CO2 trade-offs in electricity generation planning. Nat. Clim. Change 2013, 3, 10291032.

(43) Bouckaert, S.; Assoumou, E.; Selosse, S.; Maïzi, N. A prospective analysis of waste heat management at power plants and water conservation issues using a global TIMES model. Energy 2014, 68, 8091.

(44) Buras, N. Integration of Water Resource Constraints in Energy Models, 1979.

(45) van Vliet, M. T.; Vögele, S.; Rübbelke, D. Water constraints on European power supply under climate change: Impacts on electricity prices. Environ. Res. Lett. 2013, 8, 035010.

(46) Welsch, M.; Hermann, S.; Howells, M.; Rogner, H. H.; Young, C.; Ramma, I.; Bazilian, M.; Fischer, G.; Alfstad, T.; Gielen, D. Adding value with CLEWS: Modelling the energy system and its interdependencies for Mauritius. Appl. Energy 2014, 113, 1434-1445.

(47) Bartos, M. D.; Chester, M. V. The conservation nexus: Valuing interdependent water and energy savings in Arizona. Environ. Sci. Technol. 2014, 48, 2139-2149.

(48) Dubreuil, A.; Assoumou, E.; Bouckaert, S.; Selosse, S.; Marzi, N. Water modeling in an energy optimization framework-The waterscarce middle east context. Appl. Energy 2013, 101, 268-279.

(49) Al-Qattan, N.; Ross, M.; Sunol, A. K. A multi-period mixed integer linear programming model for water and energy supply planning in Kuwait. Clean Technol. Environ. Policy 2015, 17, 485-499.

(50) Huang, W.; Ma, D.; Chen, W. Connecting water and energy: Assessing the impacts of carbon and water constraints on China's power sector. Appl. Energy 2016, In Press, 1-11.10.1016/j.apenergy.2015.12.048

(51) Domènech, L.; Saurí, D. A comparative appraisal of the use of rainwater harvesting in single and multi-family buildings of the Metropolitan Area of Barcelona (Spain): Social experience, drinking water savings and economic costs. J. Cleaner Prod. 2011, 19, 598-608.

(52) Nada, N. Desalination in Saudi Arabia: An Overview. Water Arabia Conference \& Exhibition, 2013; pp 1-44.

(53) Fricko, O.; Parkinson, S. C.; Johnson, N.; Strubeggar, M.; van Vliet, M. T.; Riahi, K. Energy sector water use implications of a $2^{\circ} \mathrm{C}$ climate policy. Environ. Res. Lett. 2016, accepted.

(54) Sullivan, P.; Krey, V.; Riahi, K. Impacts of considering electric sector variability and reliability in the MESSAGE model. Energy Strategy Reviews 2013, 1, 157-163.

(55) Kumar, N.; Besuner, P.; Lefton, S.; Agan, D. Power Plant Cycling Costs 2012, DOI: 10.2172/1046269.

(56) Parkinson, S. C.; Djilali, N. Robust response to hydro-climatic change in electricity generation planning. Clim. Change 2015, 130, 475-489.

(57) Zhou, Y.; Tol, R. S. Evaluating the costs of desalination and water transport. Water Resour. Res. 2005, 41, 1-10.

(58) Phillips, B. R.; Middleton, R. S. SimWIND: A geospatial infrastructure model for optimizing wind power generation and transmission. Energy Policy 2012, 43, 291-302.

(59) Stillwell, A. S.; Webber, M. E. Geographic, technologic, and economic analysis of using reclaimed water for thermoelectric power plant cooling. Environ. Sci. Technol. 2014, 48, 4588-4595.

(60) Stillwell, A. S.; King, C. W.; Webber, M. E. Desalination and Long-Haul Water Transfer as a Water Supply for Dallas, Texas: A Case Study of the Energy-Water Nexus in Texas. Texas Water Journal 2010, $1,33-41$.

(61) Missimer, T. M.; Maliva, R. G.; Ghaffour, N.; Leiknes, T.; Amy, G. L. Managed Aquifer Recharge (MAR) Economics for Wastewater
Reuse in Low Population Wadi Communities, Kingdom of Saudi Arabia. Water 2014, 6, 2322-2338.

(62) SEC. Saudi Electricity Company Annual Report 2013, 2013.

(63) King Abdullah City for Atomic and Renewable Energy, Renwable Energy Resource Atlas, 2014. https://rratlas.kacare.gov.sa/ RRMMPublicPortal/ (accessed 2015-06-10).

(64) Al-Nory, M. T.; Brodsky, A.; Bozkaya, B.; Graves, S. C. Desalination supply chain decision analysis and optimization. Desalination 2014, 347, 144-157.

(65) Vieira, A. S.; Beal, C. D.; Ghisi, E.; Stewart, R. A. Energy intensity of rainwater harvesting systems: A review. Renewable Sustainable Energy Rev. 2014, 34, 225-242.

(66) Muga, H. E.; Mihelcic, J. R. Sustainability of wastewater treatment technologies. J. Environ. Manage. 2008, 88, 437-447.

(67) Lovins, A. Reinventing Fire: Bold Business Solutions for the New Energy Era; Chelsea Green Publishing, 2013.

(68) Black and Veatch. Cost and Performance Data for Power Generation Technologies, 2013.

(69) EIA. Updated Capital Cost Estimates for Utility Scale Electricity Generating Plants, 2013.

(70) NREL, Annual Technology Baseline (ATB) workbook, October 2015.

(71) Johnston, J.; Mileva, A.; Nelson, J.; Kammen, D. SWITCHWECC: Data, Assumptions, and Model Formulation, 2013.

(72) Riahi, K.; Dentener, F.; Gielen, D.; Grubler, A.; Jewell, J.; Klimont, Z.; Krey, V.; McCollum, D.; Pachauri, S.; Rao, S. Global Energy Assessment Chapter 17: Energy pathways for sustainable development. 2012.

(73) Flörke, M.; Kynast, E.; Bärlund, I.; Eisner, S.; Wimmer, F.; Alcamo, J. Domestic and industrial water uses of the past 60 years as a mirror of socio-economic development: A global simulation study. Global Environmental Change 2013, 23, 144-156.

(74) O’Neill, B. C.; Kriegler, E.; Riahi, K.; Ebi, K. L.; Hallegatte, S.; Carter, T. R.; Mathur, R.; van Vuuren, D. P. A new scenario framework for climate change research: the concept of shared socioeconomic pathways. Clim. Change 2014, 122, 387-400.

(75) Jiang, L.; O’Neill, B. C. Global urbanization projections for the Shared Socioeconomic Pathways Global Environ. Change 2015, 17.10.1016/j.gloenvcha.2015.03.008

(76) Beltrán, J. M.; Koo-Oshima, S. Water desalination for agricultural applications. FAO Land and water discussion paper 2006, 5,48 .

(77) Ouda, O. K. Impacts of agricultural policy on irrigation water demand: A case study of Saudi Arabia. International Journal of Water Resources Development 2014, 30, 282-292.

(78) Yermiyahu, U.; Tal, A.; Ben-Gal, A.; Bar-Tal, A.; Tarchitzky, J.; Lahav, O. Rethinking Desalinated Water Quality and Agriculture. Science 2007, 318, 920-921.

(79) Assouline, S.; Russo, D.; Silber, A.; Or, D. Balancing water scarcity and quality for sustainable irrigated agriculture. Water Resour. Res. 2015, 51, 3419-3436.

(80) FAO, Food and Agriculture Organization of the United Nations, AQUASTAT - Saudi Arabia Profile, 2014. http://www.fao.org/nr/ water/aquastat/main/index.stm (accessed 2015-06-10).

(81) Parkinson, S. C.; Johnson, N.; Jones, B.; van Vliet, M. T.; Rao, N. D.; Fricko, O.; Riahi, K.; Florke, M.; Djilali, N. Mapping global impacts of climate change and human development on municipal water demand. Submitted.

(82) Frenken, K. Irrigation in the Middle East region in figures AQUASTAT Survey-2008. Water Reports, 2009,

(83) Bredehoeft, J. D. The water budget myth revisited: why hydrogeologists model. Groundwater 2002, 40, 340-345.

(84) Taleb, H. M.; Sharples, S. Developing sustainable residential buildings in Saudi Arabia: A case study. Appl. Energy 2011, 88, 383391.

(85) McNeil, M. A.; Letschert, V. E.; Ke, J. Bottom-Up Energy Analysis System (BUENAS): An international appliance efficiency policy tool. Energy Efficiency 2013, 6, 191-217. 